\title{
Prevalence of Staphylococcus aureus and staphylococcal enterotoxins in raw pork and uncooked smoked ham-a comparison of classical culturing detection and RFLP-PCR
}

\author{
Viktoria Atanassova*, Alexandra Meindl, Christian Ring \\ Department of Food Hygiene and Microbiology (43), Centre for Food Science, School of Veterinary Medicine Hanover, \\ Bischofsholer Damm 15, D-30173 Hannover, Germany
}

Received 19 November 2000; received in revised form 26 January 2001; accepted 29 January 2001

\begin{abstract}
In many countries Staphylococcus aureus is considered to be the second or third most common pathogen causing outbreaks of food poisoning, only outnumbered by Salmonella spp. and in competition with Clostridium perfringens. Often the consumption of ham or meat containing staphylococcal enterotoxins (SE) is identified as cause of the illness. Thus, to gain an insight into the prevalence of $S$. aureus and its emetic enterotoxins in raw pork and uncooked smoked ham and to investigate how the prevalence of the pathogen is influenced during the fabrication process, a total of 135 samples of raw pork, salted meat and ready-for-sale uncooked smoked ham were examined for the prevalence of $S$. aureus and staphylococcal enterotoxins A to D (SEA-SED). To this means classical cultural methods were employed as well as molecular biological techniques (PCR) and the results were compared.

In $25.9 \%$ of all samples $S$. aureus was detected by culture whereas $51.1 \%$ of the samples showed a positive result when PCR was used for the detection of the pathogen. Fresh meat was contaminated most often. By PCR, $62.2 \%$ were identified as being S. aureus positive compared to $57.7 \%$ positive samples using the cultural technique. The detection rate during the fabrication process declined significantly. The pathogen was cultivated from $8.9 \%$ of the salted meat samples. Here, 55.6\% of the samples reacted positively in the PCR, and finally, in approximately a third of the ready-for-sale smoked hams, S. aureus genes were found. From $11.1 \%$ of these samples, the pathogen could be isolated by culture. From these results, we conclude that the PCR used in this study is more sensitive than the classical cultural method.

By PCR, one or more staphylococcal enterotoxin genes were found in 24 of the 135 examined samples. This means that $34.8 \%$ of the staphylococcal strains identified using the PCR technique were enterotoxigenic. Using the SET-RPLA, a percentage of $28.6 \%$ enterotoxigenic isolates was ascertained. No staphylococcal enterotoxin formation was detected by the SET-RPLA in ready-for-sale ham, although SE-genes were found by PCR. The detection of SE-genes by PCR is faster and easier to perform than the SET-RPLA. (C) 2001 Elsevier Science B.V. All rights reserved.
\end{abstract}

Keywords: Staphylococcus aureus; Staphylococcal enterotoxins; Food poisoning; Raw pork; Smoked ham; Comparison of cultural methods and PCR

\footnotetext{
* Corresponding author. Tel.: +49-511-8567463/8567517; fax: +49-511-8567678.

E-mail address: christian.ring@tiho-hannover.de (V. Atanassova).
} 


\section{Introduction}

Enterotoxin-producing Staphylococcus aureus plays an important role as causative organism of food intoxications. In many countries, S. aureus is considered to be the second or third most common pathogen causing outbreaks of food poisoning only outnumbered by Salmonella spp. and in competition with Clostridium perfringens (Todd, 1983; Anon., 1990; Bean and Griffin, 1990; Catteau, 1993; Bean et al., 1996). Symptoms like vomiting, abdominal pain and diarrhea usually occur approximately 2-6 h after the consumption of food containing enterotoxins (Tranter, 1990). Although some cases have been reported, a fatal outcome is very rare (Todd, 1983). Staphylococcal enterotoxins (SE) are resistant to proteolytic enzymes of the human intestinal tract and are heat stable proteins with a molecular weight of approximately 27-31 kDa (Genigeorgis, 1989; Betley et al., 1992; Balaban and Rasooly, 2000). Thus, cases of illness might occur although no viable bacteria can be isolated from the suspected foodstuff.

So far, a family of nine major serological types of SEs have been described (Balaban and Rasooly, 2000), of which the staphylococcal enterotoxins A to D are isolated most often from outbreaks of food poisoning (Bergdoll et al., 1974).

The primary reservoirs for $S$. aureus are the skin and the mucous membranes, especially of the nasopharyngeal region of birds and mammals. The pathogen is found in $30-80 \%$ of the human population and one- to two-thirds of these carriers harbour enterotoxigenic strains (Bergdoll, 1989; Isigidi et al., 1992; Wieneke et al., 1993). Thus, unhygienic treatment of food has to be considered as a major risk of contamination, and staphylococcal food poisoning is often ssociated with highly manually handled food (Catteau, 1993).

Ham is described as the vehicle most frequently identified associated with staphylococcal food poisoning, but other foods such as chicken, pork, beef, meat dishes or salads were also commonly implicated (Bryan, 1988). In Germany, several outbreaks of staphylococcal food poisoning in 1988 and 1996, when the consumption of contaminated uncooked smoked ham was identified as the source of the intoxication, and an outbreak in spring 2000 with 297 persons involved, evoked an increased interest in this pathogen and its emetic enterotoxins (Anon., 2000).

Modern molecular biological techniques for the detection and differentiation of pathogens gain more and more importance in food hygiene (Olsen et al., 1995; Wang et al., 1997; Pimbley and Patel, 1998). Methods have been described for the identification of S. aureus (Johnson et al., 1991; Brakstad et al., 1992), and staphylococcal strains harbouring copies of enterotoxin genes can be rapidly detected by PCR (Martineau et al., 1998).

In this study, we examined the prevalence of $S$. aureus and staphylococcal enterotoxins at three different stages (raw pork, salted meat, ready-for-sale uncooked smoked ham) during the fabrication process of uncooked smoked ham. A total of 135 samples was examined using classical culture methods as well as RFLP-PCR techniques. In addition, a commercially available SET-RPLA was employed for the detection of staphylococcal enterotoxins A to D. The results obtained by the various methods were compared.

\section{Material and methods}

\subsection{Samples}

A total of 135 samples was analyzed. Forty-five pig hindquarters from four different suppliers of fresh meat (supplier A to D) were unmistakably labelled at the beginning of the fabrication process of smoked ham and then divided into three groups of 15 pieces each. At three different stages during the fabrication process (raw pork, day 0; salted meat, day 42 and ready-for-sale uncooked smoked ham, day 64), samples were taken and examined. All samples were placed in an ice transporter and taken immediately to the laboratory for analyses.

\subsection{Physico-chemical parameters}

At the delivery of the samples in the laboratory, temperature (Quick ${ }^{\circledR}$-Thermometer, Novodirect, Karlsruhe, Germany), pH-value (pH192, WTW, Weilheim, Germany) and water activity (AWK-10, NAGY-Meßsysteme, Kulmbach, Germany) were determined. 


\subsection{Microbiological analyses}

\subsubsection{Reference strains}

Reference strains producing staphylococcal enterotoxins A (619/93), B (62/92), C (1299/93), D (1634/93) or no enterotoxin (8325) were kindly provided by the "National Reference Laboratory for Staphylococci" at the Robert-Koch-Institute, Wernigerode, Germany.

\subsubsection{Cultural isolation and identification of S. au- reus}

For microbiological analyses, $25 \mathrm{~g}$ of the samples were suspended in $225 \mathrm{ml}$ of Baird-Parker broth (CM0941, Oxoid, Wesel, Germany) with the addition of $0.01 \%$ potassium tellurite (SR0030, Oxoid) and homogenized aseptically. Serial decimal dilutions were then prepared from this initial dilution. Isolation of $S$. aureus was carried out by two methods: (i) plating $0.1 \mathrm{ml}$ each of the different dilutions onto the surface of both Baird-Parker (CM0275 and SR0054, Oxoid) and Kranep agar (CM0441B and SR0047, Oxoid) and incubating at $37^{\circ} \mathrm{C}$ for $48 \mathrm{~h}$ or (ii) enrichment of the samples in the Baird-Parker broth mentioned above for $24 \mathrm{~h}$ at $37^{\circ} \mathrm{C}$, subsequently plating on Baird-Parker and Kranep agar and reincubating at $37^{\circ} \mathrm{C}$ for $48 \mathrm{~h}$. Typical colonies from both methods were selected for the purpose of obtaining pure colonies on plate count agar (1.007881, Merck, Darmstadt, Germany). The strains were identified according to the criteria in Bergey's manual (Schleifer, 1986). The following tests were carried out: Gram stain, motility, oxidase (D3530-75, Becton Dickinson, Heidelberg, Germany), lipase, lecithinase and catalase production (8070.1, Roth, Karlsruhe, Germany), pigmentation, colony morphology, tube coagulase (1.13306, Merck), DNase (CM0321, Oxoid), acetoin production, sensitivity to lysostaphin (L7386, Sigma, Steinheim, Germany), lysozyme (L6876, Sigma) and furazolidone (CT022B, Oxoid) and Staphytect ${ }^{\circledR}$ test (DR0850, Oxoid).

\subsubsection{Aerobic plate count}

Serial dilutions of the samples homogenized in $0.85 \% \mathrm{NaCl}$ (1.01540, Merck) were plated on plate count agar (1.007881) and incubated under aerobic conditions for $72 \mathrm{~h}$ at $30^{\circ} \mathrm{C}$.

\subsubsection{Production of staphylococcal enterotoxins}

All S. aureus-isolates were incubated in tryptone soya broth (CM0129B, Oxoid) for $12-18 \mathrm{~h}$ at $37^{\circ} \mathrm{C}$. Subsequently, all broth cultures were $0.2 \mu \mathrm{m}$ filtered (FP30/0.2CA-S, Schleicher and Schuell, Dassel, Germany) and the filtrate was used for the staphylococcal enterotoxin test by reversed passive latex agglutination (SET-RPLA) (TD0900A, Oxoid) according to the manufacturer's instructions.

In addition, all 135 meat samples were directly examined for the prevalence of staphylococcal enterotoxins A to D. $12.5 \mathrm{~g}$ of the samples were homogenized in Dulbecco's phosphate buffered saline (PBS) (L182-01, Biochrom, Merck) and treated according to Oxoid's instructions to generate a fatfree extract. In short, fat was extracted by incubation of the minced meat samples in PBS with 1.1.2-trichlor-trifluorethan (TTE, 91440, Fluka, Steinheim, Germany) and subsequent centrifugation. The fat-free supernatant was afterwards used for the SET-RPLA.

\subsection{PCR analyses}

Preparation of bacterial DNA: $2 \mathrm{ml}$ of the inoculated and incubated Baird-Parker staphylococcal enrichment broth (see Section 2.3.2) were centrifuged (5 min, $12000 \mathrm{rpm}$ ) (Biofuge primo, 75005181, Heraeus, Osterode, Germany) at room temperature, the pellet was resuspended in $150 \mu$ l TGE buffer (25 $\mathrm{mM}$ Tris- $\mathrm{HCl}$ (1.11547, Merck), $50 \mathrm{mM}$ glucose (G-7528, Sigma), $10 \mathrm{mM} \mathrm{Na}{ }_{2}$ EDTA (1.08418, Merck)) and incubated at $37^{\circ} \mathrm{C}$ for $30 \mathrm{~min}$. After addition of $1 \mathrm{ml}$ of a $4 \mathrm{M}$ guanidine thiocyanate solution (G9277, Sigma) and $15 \mu 1$ diatomaceaous earth $\left(\mathrm{SiO}_{2}, \mathrm{D} 5384\right.$, Sigma $)$ and incubation for $2 \mathrm{~h}$ at $10^{\circ} \mathrm{C}$, another centrifugation step was performed $(5$ min, $12000 \mathrm{rpm})$. The pellet was washed several times with TGE, washing buffer $(25 \mathrm{mM}$ Tris-HCl (1.11547, Merck)), 70\% ethanol (1.00983, Merck) and acetone (8.22251, Merck). Fifteen microliters of Aqua bidest were added and the sample was heated to $56^{\circ} \mathrm{C}$ for $1 \mathrm{~h}$. After centrifugation $(10 \mathrm{~min}, 14000$ $\mathrm{rpm}, 4^{\circ} \mathrm{C}$ ) the pellet was discarded and $1 \mu \mathrm{l}$ of the supernatant was used for PCR analysis.

\subsubsection{Detection of $S$. aureus by $P C R$}

For the detection of $S$. aureus by means of PCR, $1 \mu l$ of the solution containing the bacterial DNA 


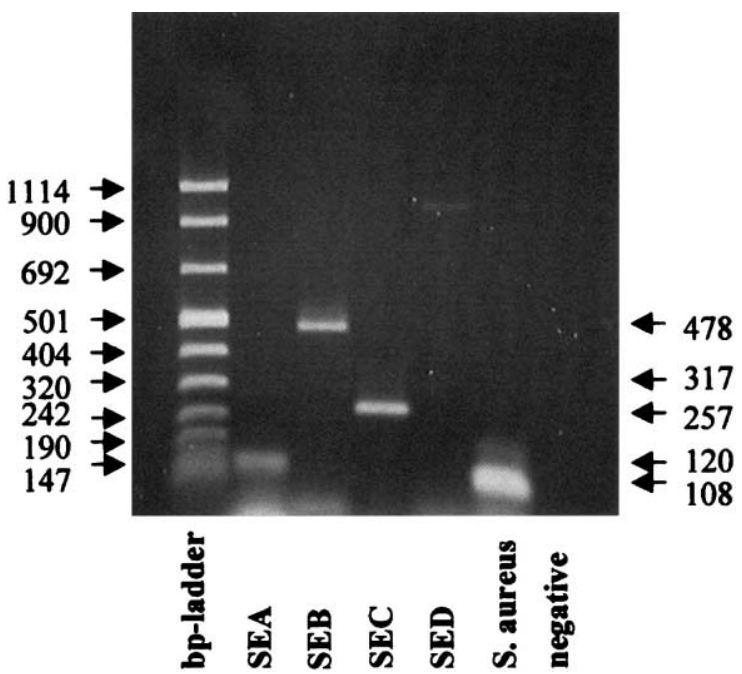

Fig. 1. Agarose gel electrophoresis of the amplified PCR fragments for the staphylococcal enterotoxin genes A to D (SEASED). S. aureus: primers described by Martineau et al. (1998) were used for the detection of $S$. aureus. Negative: negative control.

described above (see Section 2.4) was transferred to a $20-\mu 1$ PCR mixture containing $50 \mathrm{mM} \mathrm{KCl} \mathrm{(P9333,}$ Sigma), $10 \mathrm{mM}$ Tris-HCl (pH 9.0) (1.11547, Merck), $0.1 \%$ Triton X-100 (X100, Sigma), $2.5 \mathrm{mM} \mathrm{MgCl}_{2}$ (1.05835, Merck), $0.4 \mu \mathrm{M}$ (each) of the two S. aureus-specific primers, $200 \mu \mathrm{M}$ (each) of the four deoxynucleoside triphosphates (1277049, Boehringer, Mannheim, Germany), and 0.5 U Taq DNA polymerase (N8080172, Perkin Elmer, Norwalk, CT, USA). Thermal cycling was performed exactly as described by Martineau et al. (1998).

\subsubsection{Detection of staphylococcal enterotoxin genes by PCR}

For the detection of the staphylococcal enterotoxin genes A to D, the primers described by Johnson et al. (1991) were used. One microliter of the DNA preparation was added to a reaction mix according to Pollard et al. (1990) and the conditions of the PCR were as follows: DNA denaturation at $94^{\circ} \mathrm{C}$ for $2 \mathrm{~min}$, primer annealing at $55^{\circ} \mathrm{C}\left(50^{\circ} \mathrm{C}\right.$ for $\mathrm{SEC}$ and SED) for $1 \mathrm{~min}$ and DNA extension at $72^{\circ} \mathrm{C}$ for $1 \mathrm{~min}$. Only one pair of primers was added to each reaction mix and a total of 35 cycles was performed.
Fig. 1 shows the expected size of the amplified PCR fragments of enterotoxin genes A to D.

The detection of SED genes by PCR proved to be difficult and did not always work satisfactorily.

All PCR analyses were performed in a thermal cycler (Perkin Elmer 2400, Perkin Elmer) by using a recombinant Taq DNA polymerase (N8080172, Perkin Elmer). The PCR-amplified samples were analyzed by agarose gel electrophoresis using a horizontal 2\% (w/v) agarose gel (15510-019, GibcoBRL, Paisley, Great Britain) in $1 \times \mathrm{TBE}(\mathrm{pH} 8.3$; $0.09 \mathrm{M}$ Tris-HCl, 0.09 M boric acid, 2 mM EDTA) (15581-028, GibcoBRL) and $0.003 \%$ ethidium bromide (717, Sigma).

All primers used in this study were synthesized by GibcoBRL, Karlsruhe, Germany.

\section{Results}

\subsection{Physico-chemical parameters}

During the fabrication process, the average water activity $\left(a_{\mathrm{w}}\right)$ declined continuously (Table 1$)$. In contrast, the average $\mathrm{pH}$ value rose slightly during the fabrication process and reached the highest value in the ready-for-sale smoked hams (Table 1).

\subsection{Aerobic plate count}

The mean aerobic plate count reached the highest level after addition of a starter culture to the salted samples. During the further processing of the samples, the mean aerobic plate count declined again (Fig. 2).

Table 1

Development of $\mathrm{pH}$-value and water activity during the fabrication process

\begin{tabular}{llll}
\hline & Raw pork & $\begin{array}{l}\text { Salted } \\
\text { samples }\end{array}$ & $\begin{array}{l}\text { Ready- } \\
\text { for-sale } \\
\text { smoked ham }\end{array}$ \\
\hline $\begin{array}{l}\text { pH value } \\
\text { (average) }\end{array}$ & 5.75 & 5.93 & 6.04 \\
$\begin{array}{l}\text { Water activity } \\
\text { (average) }\end{array}$ & 0.992 & 0.959 & 0.937 \\
\hline
\end{tabular}




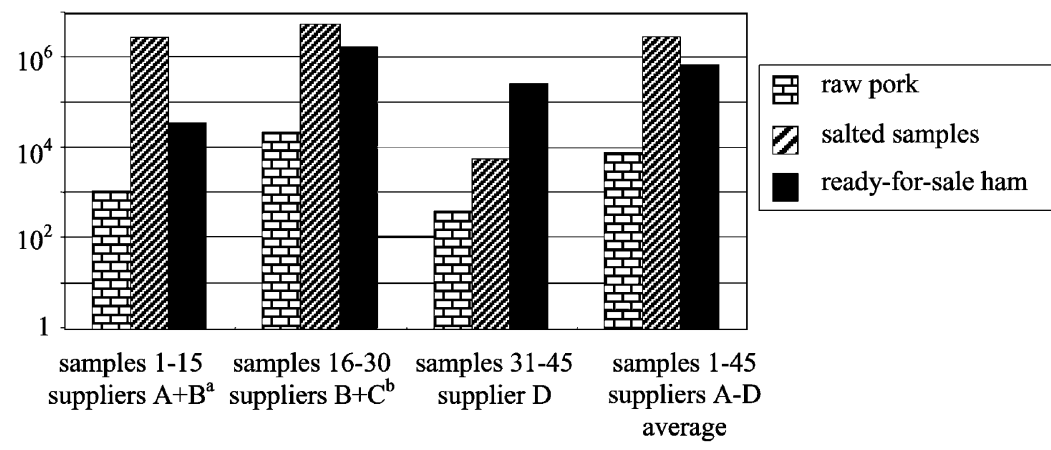

Fig. 2. Average values of the aerobic plate counts of raw pork, salted meat and ready-for-sale smoked ham from different suppliers. a: consisting of 7 samples from supplier A and B samples from supplier B, ${ }^{\text {b: }}$ consisting of 7 samples from supplier B and 8 samples from supplier C.

The aerobic plate counts of different samples from the same fabrication step differed largely (data not shown).

\subsection{Prevalence of $S$. aureus}

By means of PCR, genes of $S$. aureus were found in 69 of the total of 135 samples $(51.1 \%)$. Raw pork showed the highest prevalence with $62.2 \%$ followed by the salted meat samples $(55.6 \%) .35 .6 \%$ of the ready-for-sale smoked hams gave a positive result in the PCR (Table 2).

Using classical microbiological procedures (culture), $S$. aureus was detected in $57.7 \%$ of the raw pork, $8.9 \%$ of the salted meat samples and $11.1 \%$ of the ready-for-sale hams (Table 2). In no case was the pathogen isolated from each of the three matching samples taken at different steps of the fabrication process (raw pork, salted meat and ready-for-sale smoked ham) that were derived from the same source material. Fresh meat that was delivered by different suppliers showed divergent results in the prevalence of $S$. aureus. Whereas up to $100 \%$ of the samples from supplier A contained the pathogen, S. aureus was isolated from $21 \%$ of the raw pork from supplier B, $75 \%$ from supplier C and $60 \%$ from supplier D.

\subsection{Staphylococcal enterotoxins}

Using the primers for enterotoxin genes $\mathrm{A}$ to $\mathrm{D}$, 24 of the 135 samples showed a positive result in the PCR. This means that $34.8 \%$ of the detected $S$. aureus strains harboured one or more staphylococcal enterotoxin genes. Enterotoxin genes were found in $57.1 \%$ of the $S$. aureus-positive samples of raw pork, in $8.0 \%$ of the salted and in $37.5 \%$ of the $S$. aureus-positive samples of ready-for-sale smoked ham (Table 2).

$79.2 \%$ of the positive samples possessed one staphylococcal enterotoxin gene. In $16.7 \%$, a posi-

Table 2

Prevalence of S. aureus and staphylococcal enterotoxin genes or production, as determined by SET-RPLA

\begin{tabular}{|c|c|c|c|c|c|c|}
\hline \multirow[t]{2}{*}{ Analyte } & \multicolumn{2}{|c|}{ Raw pork } & \multicolumn{2}{|c|}{ Salted samples } & \multicolumn{2}{|c|}{ Ready-for-sale smoked ham } \\
\hline & PCR & Culture + SET-RPLA & PCR & Culture + SET-RPLA & PCR & Culture + SET-RPLA \\
\hline S. aureus ${ }^{\mathrm{a}}$ & 62.2 & 57.7 & 55.6 & 8.9 & 35.6 & 11.1 \\
\hline Enterotoxin genes ${ }^{\mathrm{b}}$ & 57.1 & 34.6 & 8.0 & 25 & 37.5 & 0 \\
\hline
\end{tabular}

\footnotetext{
${ }^{\mathrm{a}}$ Percent positive by the test method indicated.

${ }^{\mathrm{b}}$ Percent of cultured $S$. aureus strains that had genes for SEA-SED (detected by PCR) or produced enterotoxin in culture (detected by SET-RPLA)
} 
tive reaction was observed with two pairs of primers and in $4.1 \%$, three different enterotoxin genes were detected. The gene found most often $(50 \%)$ was SEA followed by SEC $(25 \%)$ and a combination of SEA and SEC (12.5\%). SED was not identified, but the PCR for the detection of this staphylococcal enterotoxin gene did not always work satisfactorily, so this result has to be looked at critically.

Using the SET-RPLA, $34.6 \%$ of the S. aureus strains isolated from fresh meat by cultural methods showed the ability to produce one or more enterotoxins. In contrast, none of the isolates from the readyfor-sale smoked hams was enterotoxigenic (Table 2). In total, $28.6 \%$ of the cultivated staphylococcal strains were producers of staphylococcal enterotoxins. A combination of SEA and SEB was found most often (data not shown). A production of three enterotoxins by one isolate has never been observed, neither has a combination of SEA and SEC. SED was not found either.

The contamination of fresh meat from different suppliers with enterotoxigenic strains of $S$. aureus varied largely. Isolates cultivated from meat delivered by supplier B have never been shown to produce enterotoxins, whereas all isolates from meat delivered by supplier A possessed the ability to produce enterotoxins (data not shown).

Although enterotoxigenic $S$. aureus strains were isolated from several of the 135 examined meat samples, when tested directly, none of these samples showed a positive reaction in the SET-RPLA, which means that none of the samples contained a detectable level of staphylococcal enterotoxins. Meat that was artificially contaminated with enterotoxinproducing reference strains served as positive control and the produced staphylococcal enterotoxins were easily detected by the SET-RPLA.

\section{Discussion}

In this study, cultural and molecular biological techniques for the detection and identification of $S$. aureus and its enterotoxins were employed and the results were compared.

Using cultural techniques, the pathogen was isolated from $25.9 \%$ of the examined 135 samples whereas $51.1 \%$ of all samples were tested positively by PCR.
S. aureus was cultivated from $57.7 \%$ of the raw pork. This percentage is much higher than the $22.7 \%$ positive samples described by Schraft et al. (1992) for pig hindquarters. We want to point out that in this study, S. aureus was in some cases only isolated after enrichment (incubation of the samples in Baird-Parker broth with the addition of $0.01 \%$ potassium tellurite for $24 \mathrm{~h}$ ), whereas Schraft et al. took swab samples of the meat surface that were plated onto agar directly afterwards. It seems possible that low numbers of staphylococci might not have been detected by this method.

In this study, raw pork delivered by different suppliers showed striking divergences in the results of the aerobic plate counts and in the prevalence of S. aureus. Whereas the pathogen was cultivated from $100 \%$ of the raw pork delivered by supplier A and all these positive samples were also shown to harbour enterotoxigenic strains of $S$. aureus, culturing detection was positive only in $21 \%$ of the raw pork samples from supplier B, $60 \%$ from supplier D and $75 \%$ from supplier C. At a high percentage the isolates cultivated from the meat samples delivered by the same supplier revealed identical characteristics (e.g. the ability to produce enterotoxins or the kind of the enterotoxins produced). Thus, it may be concluded that the pathogen did not originate directly from the animals, but was spread onto the meat during slaughter or further processing. One possible source of contamination is, for example, the handling of meat by human carriers of $S$. aureus. Humans as well as pigs can harbour even enterotoxigenic strains of $S$. aureus on their skin or mucosal membranes without showing any symptoms of illness. Therefore, to ensure the impeccable quality of the product, the outmost hygienic precautions have to be taken during the slaughter and further processing of the meat.

The meat examined in this study was delivered to the manufacturer of the hams by four different suppliers. Unfortunately, no specific information on these suppliers and on the handling of the meat prior to the delivery could be obtained.

Cultural techniques revealed a prevalence of $S$. aureus in salted meat samples of $8.9 \%$. However, using PCR, $55.6 \%$ of the salted meat samples gave a positive result. The difference in these results can be explained by the higher sensitivity of the molecular 
biological method. At the time point of salting growth conditions for $S$. aureus are negatively influenced by the addition of starter cultures. Thus, competition arises and lower numbers of the pathogen are isolated by culturing detection although the aerobic plate count rises. Other authors confirm these results (Lücke and Hechelmann, 1987; Genigeorgis, 1989; González-Fandos et al., 1994). The correct dosage of salt is essential for the sensorial and microbiological quality and the conservation of cured meat. Although pickling salt has a hampering effect on the growth of $S$. aureus, high salt concentrations in cured meat often favour a selective increase of $S$. aureus, a pathogen which is able to multiply at a water activity of 0.86 at which other microorganisms are often no longer viable. During the further fabrication process, growth conditions for microorganisms worsen even more (decreasing water activity, smoke) and the aerobic plate count decreases. But measurements of the $\mathrm{pH}$-value and the water activity clearly show that according to data presented in literature (Genigeorgis, 1989; Untermann and Müller, 1992), S. aureus can survive and even produce staphylococcal enterotoxins in ready-for-sale smoked hams.

By PCR, S. aureus genes were detectable in $35.6 \%$ of the ready-for-sale smoked hams and in approximately a third of these positive samples, staphylococcal enterotoxin genes were also found. In contrast, using cultural techniques, the pathogen was isolated only from $11.1 \%$ and in none of the isolates was enterotoxin formation detected by the SETRPLA.

From the 45 pig hindquarters that were used for the production of the smoked hams, samples were taken at three steps during the fabrication process (from the raw pork, the matching salted samples and the ready-for-sale smoked hams). In no case was $S$. aureus isolated from each of the three matching samples by culture. The sensitivity of the cultural technique might not have been sufficient to detect very low levels of the pathogen or S. aureus-free samples might have been newly (re-)contaminated during the fabrication process. This thesis is further underlined by the observation that in some cases, the $S$. aureus strains cultivated from the three matching samples differed in their ability to produce staphylococcal enterotoxins and in the kind of the enterotoxin(s) produced. For example, once, a SEA and
SEB producing isolate was cultivated from a salted sample, whereas the isolate from the matching piece of raw pork showed only SEB formation. It seems possible that during the production process, new or re-contamination might have occurred, for example, by transmission of the pathogen from the hands of the workers. However, since due to practical restrictions of the method, only a limited number of isolates from each sample could be further analyzed, it cannot be excluded that in some samples, various strains of $S$. aureus might have been present and that not all of them were detected.

All meat samples were also examined directly for the presence of staphylococcal enterotoxins with the SET-RPLA, but in no case was a positive result found. The preparation of the samples for the test proved to be difficult and time-consuming especially since the high fat content had to be considered. However, the applicability of the test for the examination of food samples had been proven before (Rose et al., 1989) and was also verified in this study by testing artificially contaminated meat samples. Thus, it is concluded that either no staphylococcal enterotoxin formation took place under the conditions used during the fabrication process or that the amount of enterotoxins was too low to be detected by the SET-RPLA. The samples were not examined for the occurrence of SEE, which is seldom associated with outbreaks of food intoxication and is said to react with anti-SEA (Wieneke, 1988), or SEG to SEJ.

The molecular biological detection of staphylococcal enterotoxins by PCR is easier and faster to perform and of higher sensitivity. However, for some as yet unknown reasons, the detection of the SED gene proved to be difficult and did not always work satisfactorily. Results concerning this staphylococcal enterotoxin gene have therefore to be looked at critically.

In this study, in some cases, different and/or more manifold SE-gene combinations were detected by PCR than staphylococcal enterotoxins were found in the same sample using the SET-RPLA. As already explained above, for practical reasons, only a limited number of isolates was used for the SET-RPLA. In contrast, several $S$. aureus strains might have grown in the Baird-Parker broth used for PCR analyses (see Section 2.4), which were subsequently detected. 
Another explanation might be that the PCR amplicon sought in each gene is much less than the total genetic sequence of that gene, so that the gene might be defective, or might not be transcribed/translated due to repressors or other external genetic factors.

We have no satisfactory explanation why the far more sensitive PCR method detected enterotoxin genes in only $8.0 \%$ of the salted samples, whereas $25 \%$ of the isolates derived from these samples by culturing detection were identified as being enterotoxigenic by the SET-RPLA.

Enterotoxins A and D are the serotypes most commonly associated with outbreaks of food poisoning (Bergdoll et al., 1974). In this study, staphylococcal enterotoxin A was found most often, but we did not find any staphylococcal enterotoxin D (genes) by either SET-RPLA or PCR.

To summarize, it may be said that the sensitivity of the PCR technique for the identification and detection of $S$. aureus is higher than that of classical cultural procedures. Since PCR detects pathogens at DNA level, a positive result does not necessarily mean that the microorganism is still viable. This problem can in part be overcome by incubation of the samples in a selective enrichment broth, so that viable pathogens multiply prior to their detection.

In fact, there is an interval long after death or inactivation of bacteria during which the nucleic acid targeted by PCR primers remains intact and a positive PCR result is obtained, although the pathogen no longer causes any health hazard for the consumer. However, a positive PCR result for S. aureus shows that the pathogen, at potentially toxigenic levels, has been present in the sample. Since staphylococcal enterotoxins might still be contained in the food, although no viable bacteria are left, such samples have to be looked at critically.

\section{Conclusion}

Molecular biological procedures for the detection and identification of microorganisms and their (entero)toxins gain more and more importance in food hygiene. In comparison to classical cultural techniques, they are not only faster and more sensitive but are often also easier to perform.

In this study, we examined the prevalence of $S$. aureus and its enterotoxins in raw pork and smoked hams produced from this meat and compared the results using PCR with the ones achieved by culturing detection. In total, the pathogen was found in $25.9 \%$ of the 135 samples by cultural techniques. By PCR, S. aureus genes were detected in $51.1 \%$ of the examined samples. From $11.1 \%$ of the ready-for-sale smoked hams, $S$. aureus was isolated and $35.6 \%$ of this product reacted positively in the PCR. Concerning the consumers' health, these results have to be looked at critically. Although the prevalence and number of the pathogen decreases during the further production process, to minimize potential health hazards that can be caused by contamination of products with $S$. aureus, special attention should be paid to the microbiological status of the source material used for the production of smoked ham. High bacterial loads cause not only sensorical deviations and technological problems but also contain considerable risks for human health.

Good manufacturing practice and high hygienic levels during the fabrication process help in preventing new or re-contamination of the products with S. aureus.

In our study, PCR proved to be more sensitive for the detection and identification of $S$. aureus than classical cultural methods. In comparison to the SET-RPLA (genes of) staphylococcal enterotoxins can be detected more rapidly and much easier by the PCR technique described here.

\section{Acknowledgements}

The Fritz-Ahrberg-Stiftung, Germany is gratefully acknowledged for their support and funding of this project. We would like to thank the "National Reference Laboratory for Staphylococci" at the RobertKoch-Institute, Wernigerode for the staphylococcal reference strains.

\section{References}

Anon., 1990. Ministeridad de Sanidad y Consumo. Bol. Epidemiol. Semanal. 1873, 273-274.

Anon., 2000. Lebensmittelvergiftungen durch toxinbildende Staphylokokken. Epidemiol. Bull. 31, 246-249.

Balaban, N., Rasooly, A., 2000. Staphylococcal enterotoxins. Int. J. Food Microbiol. 61 (1), 1-10. 
Bean, N.H., Griffin, P.M., 1990. Foodborne disease outbreaks in the United States, 1973-1987: pathogens, vehicles and trends. J. Food Prot. 53, 804-817.

Bean, N.H., Goulding, J.S., Lao, C., Angulo, F.J., 1996. Surveillance for foodborne-disease outbreaks-United States, 19881992. Morb. Mortal. W. Rep. 45 (SS-5), 1-66.

Bergdoll, M.S., 1989. Staphylococcus aureus. In: Doyle, M.P. (Ed.), Foodborne Bacterial Pathogens. Marcel Dekker, New York, pp. 463-523.

Bergdoll, M.S., Czop, J.K., Gould, S.S., 1974. Enterotoxin synthesis by the staphylococci. Ann. N. Y. Acad. Sci. 236, 307-316.

Betley, M.J., Borst, D.W., Regassa, L.B., 1992. Staphylococcal enterotoxins, toxic shock syndrome toxin and streptococcal pyrogenic exotoxins: a comparative study of their molecular biology. Chem. Immunol. 55, 1-35.

Brakstad, O.G., Aasbakk, K., Maeland, J.A., 1992. Detection of Staphylococcus aureus by polymerase chain reaction amplification of the nuc gene. J. Clin. Microbiol. 30 (7), 1654-1660.

Bryan, F.L., 1988. Risks associated with vehicles of foodborne pathogens and toxins. J. Food Prot. 51 (6), 498-508.

Catteau, M., 1993. Infections microbiennes d'origine alimentaire. Ann. Falsif. Expert. Chim. 86, 17-24.

Genigeorgis, C.A., 1989. Present state of knowledge on staphylococcal intoxication. Int. J. Food Microbiol. 9, 327-360.

González-Fandos, E., Otero, A., Sierra, M., Garcia-Lopez, M.L., Prieto, M., 1994. Effect of three commercial starters on growth of Staphylococcus aureus and enterotoxins (A-D) and thermonuclease production in broth. Int. J. Food Microbiol. 24 (1-2), 321-327.

Isigidi, B.K., Mathieu, A.-M., Devriese, L.A., Godard, C., Van Hoof, J., 1992. Enterotoxin production in different Staphylococcus aureus biotypes isolated from food and meat plants. J. Appl. Bacteriol. 72 (1), 16-20.

Johnson, W.M., Tyler, S.D., Ewan, E.P., Ashton, F.E., Pollard, D.R., Rozee, K.R., 1991. Detection of genes for enterotoxins, exfoliative toxins, and toxic shock syndrome toxin 1 in Staphylococcus aureus by the polymerase chain reaction. J. Clin. Microbiol. 29 (3), 426-430.

Lücke, F., Hechelmann, H., 1987. Starter cultures for dry sausages and raw ham. Fleischwirtschaft 67, 307-314.

Martineau, F., Picard, F.J., Roy, P.H., Ouelette, M., Bergeron, M.G., 1998. Species-specific and ubiquitous-DNA-based as- says for rapid identification of Staphylococcus aureus. J. Clin. Microbiol. 36, 618-623.

Olsen, J.E., Aabo, S., Hill, W., Notermans, S., Wernars, K., Granum, P.E., Popovic, T., Rasmussen, H.N., Olsvik, Ø., 1995. Probes and polymerase chain reaction for detection of food-borne bacterial pathogens. Int. J. Food Microbiol. 28, $1-78$.

Pimbley, D.W., Patel, P.D., 1998. A review of analytical methods for the detection of bacterial toxins. J. Appl. Microbiol. Symp. Suppl. 84, 98S-109S.

Pollard, D.R., Johnson, W.M., Lior, H., Tyler, S.D., Rozee, K.R., 1990. Rapid and specific detection of verotoxin genes in Escherichia coli by the polymerase chain reaction. J. Clin. Microbiol. 28, 540-545.

Rose, S.A., Bankes, P., Stringer, M.F., 1989. Detection of staphylococcal enterotoxins in dairy products by the reversed passive latex agglutination (SET-RPLA) kit. Int. J. Food Microbiol. 8, 65-72.

Schleifer, K.H., 1986. Family I. Micrococcaceae Prevot 1961, $31^{\mathrm{AL}}$. In: Sneath, P.H.A., Mair, S., Sharpe, M.E., Holt, J.G. (Eds.), Bergey's Manual of Systematic Bacteriology, vol. 2, The Williams and Wilkins, Baltimore, pp. 1003-1035.

Schraft, H., Kleinlein, N., Untermann, F., 1992. Contamination of pig hindquarters with Staphylococcus aureus. Int. J. Food Microbiol. 15, 191-194.

Todd, E.C.D., 1983. Foodborne disease in Canada-a 5-year summary. J. Food Prot. 46, 650-657.

Tranter, H.S., 1990. Foodborne staphylococcal illness. Lancet 336 (8722), 1044-1046.

Untermann, F., Müller, C., 1992. Influence of $\mathrm{a}_{\mathrm{w}}$-value and storage temperature on the multiplication and enterotoxin formation of staphylococci in dry-cured raw hams. Int. J. Food Microbiol. 16 (2), 109-115.

Wang, R.F., Cao, W.-W., Cerniglia, C.E., 1997. A universal protocol for PCR detection of 13 species of foodborne pathogens in foods. J. Appl. Microbiol. 83, 727-736.

Wieneke, A.A., 1988. The detection of enterotoxin and toxic shock syndrome toxin-1 production by strains of Staphylococcus aureus with commercial RPLA kits. Int. J. Food Microbiol. 7, 25-30.

Wieneke, A.A., Roberts, D., Gilbert, R.J., 1993. Staphylococcal food poisoning in the United Kingdom, 1969-90. Epidemiol. Infect. 110, 519-531. 